\title{
BMJ Global Health Bridging the 'two communities': how an emerging primary healthcare global research consortium can help achieve universal health coverage in low and middle-income countries
}

\author{
Ejemai Amaize Eboreime ${ }^{\bullet 1,2}$
}

To cite: Eboreime EA. Bridging the 'two communities': how an emerging primary healthcare global research consortium can help achieve universal health coverage in low and middle-income countries. BMJ Glob Health 2019;4:e001573. doi:10.1136/ bmjgh-2019-001573

Received 22 March 2019 Revised 30 March 2019 Accepted 1 April 2019

Check for updates

(C) Author(s) (or their employer(s)) 2019. Re-use permitted under CC BY-NC. No commercial re-use. See rights and permissions. Published by BMJ.

${ }^{1}$ Department of Planning, Research \& Statistics, National Primary Healthcare Development Agency, Abuja, Nigeria

${ }^{2}$ Centre for Health Policy, University of the Witwatersrand, Johannesburg-Braamfontein, South Africa

Correspondence to Dr Ejemai Amaize Eboreime; ejemaim@gmail.com
We had done so much work, earned recognition, but solved nobody's problem.

$$
\text { (Dr Abhay Bang) }{ }^{1}
$$

\section{INTRODUCTION}

World leaders reconvened at the 40th anniversary of the 1978 Alma Ata declaration to renew their commitment to primary healthcare (PHC) as the key to attaining Health for All, the goals of universal health coverage (UHC) and the sustainable development goals (SDGs). ${ }^{2}$ Among affirmations made was the commitment to apply knowledge in order to support multisectoral stakeholder collaborations to strengthen PHC systems. The Declaration of Astana recognised that effective knowledge generation and translation strategies focused on PHC are critical to attaining these global goals. This recognition echoes a global call for evidence-informed healthcare policy and decision-making for over two decades. ${ }^{3}$

However, one challenge is Nathan Caplan's theorised 'two communities': the research community (knowledge producers) and the policy/practice community (knowledge consumers), each with intrinsically different perspectives and priorities. ${ }^{4}$ The association between evidence and policy is not always rational or sequential, given that researchers may not produce the evidence and knowledge needed, policymakers may not always choose to take evidence-informed actions, or may choose to use evidence in ways unacceptable to researchers such as to support predetermined positions or decisions. ${ }^{5}$ The recent World Report on Health Policy and Systems Research also noted that the evidence-policy-implementation continuum is quite
Summary box

The quantity of knowledge produced by the research community in Low and Middle-Income Countries (LMICs) has increased substantially in recent years.

- Knowledge producers may consider their research relevant for the policy and practice community but knowledge consumers often question the utility of this research in real-world policymaking.

- Bridging the gap between these 'two communities' is critical to attaining universal health coverage and sustainable development goals through high performing primary healthcare (PHC) systems.

- An emerging PHC global research consortium can help bridge this gap and produce acceptable contextual evidence for PHC performance improvements in LMICs.

fragmented as practitioners operate across various paradigms, organisational structures and tiers, and the evidence produced is not always aligned with priority knowledge gaps. ${ }^{6}$ This gap hampers the ability of new evidence to be used to address the persisting poor performance of health systems and to achieve the promise of UHC and the SDGs. ${ }^{7}$ Consequently, improving the relationship between the two communities is critical to encouraging the production of knowledge that is needed and utilisation of this newly produced evidence in policy planning and implementation. ${ }^{58}$ Recently, there have been global efforts to bridge the research-policy-implementation gap but significant work is still needed in how research is prioritised, produced and used. ${ }^{9}$

The quantity of knowledge produced by the research community in LMICs has increased substantially in recent years, which in theory should accelerate uptake given local production. ${ }^{10}$ However, while these knowledge producers may consider their research 
relevant for the policy and practice community, policymakers and implementers often still question the utility of this research in real-world policymaking and not reflecting the need for local contextualisation. ${ }^{6}$ Therefore, in order to achieve the Astana declaration goals and broader SDG and UHC, it is crucial for the global health community to strengthen existing and develop new models to ensure that the knowledge produced reflects the needs of policymakers and implementers and is translated effectively into action. One approach is improving the partnership and dialogue between PHC researchers, policymakers, providers and other interest groups to produce and apply the new knowledge needed. Another important action is to develop new pathways and communities of researchers needed to prioritise and produce the knowledge needed. ${ }^{11}$

\section{BRIDGING THE GAP: THE VALUE OF A NEW GLOBAL PHC CONSORTIUM}

Given the importance of PHC in the attainment of UHC and the SDGs, one of these recent efforts in LMICs has been the work to develop a new global research consortium with the goal of producing prioritised evidence that is relevant to policymakers and implementers seeking to improve PHC systems and delivery. The idea for this proposed PHC measurement and implementation consortium emerged from work by the Primary Healthcare Performance Initiative (PHCPI, www.improvingPHC.org) which recognised the knowledge gaps in how to measure and improve key functions of PHC in LMICs. The consortium is designed to be an interdisciplinary global research network prioritising LMIC leadership and including researchers and policymakers from academic institutions, government agencies, international organisations and non-governmental organisations. The diverse nature of a consortium based in LMICs partnering with researchers across high-income, middle-income and low-income countries, creates an opportunity to close this research-policy-implementation gap in PHC. Further, it creates a platform for harnessing the resources needed to generate and translate country-prioritised, policy-relevant evidence to support better measurement, implementation and improvement efforts for PHC in LMICs. The consortium also has the potential to build needed capacity in LMICs to increase leadership and capacity for future work.

Building on the PHCPI framework and a scoping review of existing PHC research, ${ }^{12}$ the effort identified four priority research areas where there were gaps in measurement and improvement knowledge. Quality, safety and performance Management; PHC policies and governance; organisation and models of care; PHC financing. Work was funded to complete evidence gap maps and a multi country prioritisation process described in the introduction to this supplement.

This supplement is a compendium of outcomes of these foundational processes. It presents findings on knowledge gaps relating to PHC from diverse LMIC contexts such as sub-Saharan Africa and the Asia-Pacific regions and Central and Latin America. The findings presented and the questions raised in the articles are important to catalyse a contextual agenda for the consortium as well as inform broader research efforts targeting PHC improvement. For example, a systematic scoping review by Bresick and colleagues revealed a paucity of validated measures and fit-for-purpose instruments, as well as poor suitability of identified evidence base to inform the design of performance measurements and management policies and programme in LMICs (Bresick et al, 2019). Another study conducted by Angell et al seeking to generate a stakeholder-led research agenda in the area of PHC financing revealed a disparity between research questions prioritised by stakeholders and existing questions addressed by current research (Angell et al, 2019). The findings from the articles included in this supplement reinforce the necessity for consortium that can drive evidence-informed decision making and PHC performance improvements through a better and more inclusive approach to determining what research is needed as well as how it should be done. Also importantly, the series of studies set a foundational agenda for the consortium to focus on context-specific evidence related to the most effective approaches for improving PHC performance in LMICs.

The issues raised in this supplement reflect my thoughts and experiences as an actor in both the knowledge producing and the knowledge consuming communities. Working in Nigeria's PHC policy space, I have been concerned that policy decisions are often made without utilisation of contextual evidence. On the other hand, being affiliated with research institutions across the sub-Saharan Africa, I also find that knowledge being produced is often skewed to address areas of interest to funders and researchers rather than the priority knowledge needs of the research consumers. It is therefore important that stakeholders across the knowledge production to consumption spectrum interact effectively to harmonise and contextualise priority areas so as to streamline funding accordingly.

For the consortium to be effective, focus must also be given to improving capacity within and across countries given the diversity in resources and research experience; ensuring an appropriate interdisciplinary/functional mix (such as academia, service providers, policymakers and implementers); as well as to the importance of an LMIC driven prioritisation and production. If successful, this research consortium can produce the knowledge and insights needed by policymakers and implementers to know how to better identify and address the quality gaps in PHC and accelerate the work needed to ensure that UHC has the quality, effectiveness, equity and sustainability needed.

\section{CONCLUSION}

The emerging research consortium seeks to answer key questions on how to understand and overcome 
both cross-cutting and context specific bottlenecks to PHC. While serving as a knowledge translation platform, it should also address the capacity to implement evidence-informed strategies, which is noted to be a deficiency in many PHC delivery systems. ${ }^{713-15}$ Thus, a system is desired that not only translates the "science-derived knowledge' from researchers to evidence users, but also converts this to the 'practical art of implementation' required to make the impact. In this way, actual problems will be solved following the interlocking activities of knowledge producers and knowledge users: the two becoming one community.

Contributors A solely authored commentary on a supplement.

Funding The authors have not declared a specific grant for this research from any funding agency in the public, commercial or not-for-profit sectors.

Competing interests None declared.

Patient consent for publication Not required.

Provenance and peer review Not commissioned; internally peer reviewed.

Data sharing statement № additional data are available.

Open access This is an open access article distributed in accordance with the Creative Commons Attribution Non Commercial (CC BY-NC 4.0) license, which permits others to distribute, remix, adapt, build upon this work non-commercially, and license their derivative works on different terms, provided the original work is properly cited, appropriate credit is given, any changes made indicated, and the use is non-commercial. See: http://creativecommons.org/licenses/by-nc/4.0/.

\section{REFERENCES}

1. Abhay Bang. Putting people at the heart of research. 2018. Available: https://idronline.org/putting-people-heart-research/ [Accessed 7 Jan 2019].
2. Beard TC, Redmond S. Declaration of Alma-Ata. The Lancet 1979;313:217-8.

3. Ridde V. Need for more and better implementation science in global health. BMJ Glob Health 2016;1:e000115.

4. Caplan N. The Two-Communities theory and knowledge utilization. Am Behav Sci 1979;22:459-70.

5. Buse K, Mays N, Walt G, et al. Making Health Policy. Berkshire: Open University Press, 2005.

6. WHO. World report on health policy and systems research. 2017. Available: http://apps.who.int/bookorders [Accessed 7 Jan 2019]

7. Eboreime EA, Nxumalo N, Ramaswamy R, et al. Effectiveness of the Diagnose-Intervene- Verify-Adjust (Diva) model for integrated primary healthcare planning and performance improvement: an embedded mixed methods evaluation in Kaduna state, Nigeria. BMJ Open. In Press 2019;9.

8. Wehrens R. Beyond two communities - from research utilization and knowledge translation to co-production? Public Health 2014;128:545-51.

9. Peters DH. Health policy and systems research: the future of the field. Health Res Policy Syst 2018;16.

10. English KM, Pourbohloul B. Increasing health policy and systems research capacity in low- and middle-income countries: results from a bibliometric analysis. Health Res Policy Syst 2017;15.

11. Uneke CJ, Ezeoha AE, Uro-Chukwu HC, et al. Promoting researchers and Policy-Makers collaboration in evidence-informed policy-making in Nigeria: outcome of a two-way Secondment model between university and health Ministry. Int $J$ Health Policy Manag 2017;7:522-31.

12. Bitton $\mathrm{A}$, Ratcliffe $\mathrm{HL}$, Veillard $\mathrm{JH}$, et al. Primary health care as a foundation for strengthening health systems in low- and middleincome countries. J Gen Intern Med 2017:32:566-71.

13. Eboreime E, Nxumalo N, Ramaswamy R. Implementing a model for improving integrated primary healthcare planning and performance: an effectiveness evaluation of Diva in Kaduna, Nigeria. Cochrane Database Syst Rev 2017.

14. Eboreime EA, Abimbola S, Obi FA, et al. Evaluating the sub-national fidelity of national initiatives in decentralized health systems: integrated primary health care governance in Nigeria. BMC Health Serv Res 2017;17.

15. Eboreime EA, Eyles J, Nxumalo N, et al. Implementation process and quality of a primary healthcare system improvement initiative in a decentralized context: a retrospective appraisal using the quality implementation framework. Int J Heal Plann Mgmt 2018. 